BULLETIN Bulletin hispanique

HISPANIQUE Université Michel de Montaigne Bordeaux

119-1 | 2017

Autorité et pouvoir dans le théâtre du Siècle d'Or

\title{
Autoridad y decoro en el teatro
}

ideas políticas y malos gobernantes en Bances Candamo

\section{J. Enrique Duarte}

\section{OpenEdition}

\section{Journals}

Edición electrónica

URL: http://journals.openedition.org/bulletinhispanique/4793

DOI: 10.4000/bulletinhispanique.4793

ISBN: 979-10-300-0142-6

ISSN: 1775-3821

Editor

Presses universitaires de Bordeaux

Edición impresa

Fecha de publicación: 15 junio 2017

Paginación: 117-132

ISBN: 979-10-300-0141-9

ISSN: 0007-4640

Referencia electrónica

J. Enrique Duarte, «Autoridad y decoro en el teatro », Bulletin hispanique [En línea], 119-1 | 2017,

Publicado el 17 junio 2020, consultado el 23 septiembre 2020. URL : http://journals.openedition.org/ bulletinhispanique/4793; DOI : https://doi.org/10.4000/bulletinhispanique.4793 


\title{
Autoridad y decoro en el teatro: ideas políticas y malos gobernantes en Bances Candamo
}

\author{
J. Enrique Duarte \\ GRISO-Universidad de Navarra
}

Le théâtre de Francisco Bances Candamo, en relation directe avec les règles dramatiques, montre un propos éducatif constant. Lauteur étudie la présence de quelques idées politiques fondamentales et il analyse les modèles des tyrans dans deux pièces : Por su rey y por su dama et El esclavo en grillos de oro, en se fondant sur les théories politiques de quelques auteurs de l'époque.

Mots-clés: Bances Candamo, mauvais dirigeants, Por su rey y por su dama, El esclavo en grillos de oro.

El teatro de Francisco Antonio Bances Candamo muestra una relación directa con su preceptiva dramática y una preocupación por un propósito educativo. El autor estudia la presencia de algunas ideas políticas esenciales examinando los modelos de malos gobernantes en dos comedias: Por su rey y por su dama y El esclavo en grillos de oro apoyándose en la teoría política de la época.

Palabras clave: Bances Candamo, malos gobernantes, Por su rey y por su dama, El esclavo en grillos de oro.

Francisco Antonio Bances Candamo's theatre shows a direct relation with his theory of drama, and a deep concern of educational purpose. The author of this article studies the presence of some basic essential political ideas and examines the models of tyranny in two works: "Por su Rey y por su Dama" and "El Esclavo en Grillos de Oro", using the theories of some political authors of this period.

Keywords: Bances Candamo, tyranny, Por su rey y por su dama, El esclavo en grillos de oro. 


\section{INTRODUCCIÓN}

Para acercarse el estudio de la obra de Bances Candamo, tarea muy atractiva porque nos permite la comparación de su teorización (con la incompleta Teatro de los teatros) y su producción áulica (teatro cortesano para ser representado delante del rey), hay que partir de tres premisas : la primera de ellas es su valoración del decoro, tanto dramático como moral, al que relaciona directamente con la verosimilitud ${ }^{1}$; en segundo lugar, hay que destacar la finalidad de ese teatro, que consiste en esencia en el entretenimiento del rey y su educación ${ }^{2}$; y por último hay que tener en cuenta la importancia de las autoridades, la búsqueda de documentación para cumplir con las altas exigencias de la verosimilitud, condición a la que Bances somete su teatro ${ }^{3}$.

\section{IdeAs políticas que Recorren la obra de Bances}

Debemos empezar recordando que García Castañón ha propuesto una imagen de Bances seguidor de las teorías de Maquiavelo y, por lo tanto, inaugurando una tendencia de estima por sus ideas que se produciría a lo largo del siglo XVIII. En un artículo dedicado a comentar la comedia Sangre, valor y fortuna, le parece que el título, repetido en distintas ocasiones a lo largo de la obra como un leitmotiv, insiste en conceptos claves de la teoría de Maquiavelo como la fortuna o el valor, la conocida virtus clásica, las cualidades propias del varón (del vir) y que no pueden ser confundidas con la virtud cristiana ${ }^{4}$.

$\mathrm{El}$ argumento me parece débil porque lo esencial de la teoría del maestro italiano no es si los reinos dependen de la fortuna o, incluso, si el hombre clásico tenía más virtud (más valor) debido, sobre todo, a la sangre de los sacrificios de la religión pagana (Maquiavelo 1961: 494), frente a la supuesta pusilanimidad cristiana, elemento que discuten con ardor los teóricos católicos

1. Bances Candamo 1970: 35: «Precepto es de la comedia inviolable que ninguno de los personajes tenga acción desairada, ni poco correspondiente a lo que significa, que ninguno haga una ruindad ni cosa indecente». Para la importancia de la verosimilitud, ver Duarte 2005: 283307.

2. Ibid., p. 57 : «Son las comedias de los reyes unas historias vivas que, sin hablar con ellos, les han de instruir con tal respeto que sea su misma razón quien de lo que ve tome sus advertencias, y no el ingenio quien se las diga. Para este decir sin decir, ¿quién dudará que sea menester gran arte?». Ver Arellano (1998: 49) donde se explica esta expresión del decir sin decir, mal interpretada por Moir y otros críticos.

3. Ibid., p. 50-51: «Hablaré yo en una comedia de los trajes, calles, edificios y costumbres de alguna corte extranjera y lo está oyendo el embajador que residió, el soldado que estuvo y el curioso que peregrinó en ella». Es muy esclarecedor el artículo de Oteiza (2011).

4. García Castañón (1991b: 59): «No me parece casual la aparición de estos tres conceptos maquiavélicos en la obra de Bances Candamo. Más bien creo que se trata del fruto de una lectura de Il principe y del intento por parte de Bances Candamo de aplicar sus ideas sobre el Estado a la realidad española». Insiste este autor en (1991a). 
(Ribadeneyra 1942: 168 y ss.). Lo esencial, creo yo, es la radical independencia de la política frente a otros elementos, la religión o la ética, que se convierten en asistentas fieles de los fines particulares del gobernante para conseguir el poder o mantenerlo 5 . Y este pensamiento no se encuentra en Bances, en sus buenos gobernantes, aquellos que pueden servir de modelo al rey en su teatro pedagógico.

Por el contrario, en Bances, la primera idea política que encontramos en nuestras lecturas es la exaltación de la casa de Austria y su identificación con la defensa del catolicismo, como muy bien ha demostrado Ignacio Arellano ${ }^{6}$ (2011), quien analiza esta identificación de política y religión incluso en la escenografía de las obras teatrales. Los siguientes versos pertenecientes a $\mathrm{La}$ restauración de Buda resultan ser un ejemplo paradigmático:

Música

\author{
¡Viva la gran casa de Austria \\ cuyo fervoroso celo \\ alma es de la religión, \\ gloria es de la fe, supuesto \\ que en el católico y cesáreo reino \\ columna del impíreo es hoy su imperio. (vv. 3160-3165)
}

Esta identificación de la religión y el poder se muestra con virulencia en una reacción de los escritores católicos frente a las doctrinas de Maquiavelo. Un ejemplo, de los muchísimos que podemos espigar, es el de Giovanni Botero quien, en su tratado La razón de Estado, reclama esta unión en diversos pasajes, como este del libro II, cap. 12:

La religión es el fundamento de todo principado, pues viniendo de Dios toda potestad y no adquiriéndose la gracia y el favor de Dios sino con la religión, otro tipo de fundamento sería ruinoso. Por la religión se granjea el príncipe el amor de Dios y ¿qué cosa puede temer quien tiene a Dios de su parte? (Botero 1962: 123).

Los teóricos de la política cristiana siempre acaban en un punto: que las teorías de Maquiavelo son profundamente irracionales, repugnan a la razón humana, porque atienden más a los caprichos del gobernante que a las verdaderas necesidades del reino. Curiosamente, uno de los personajes de Por su rey y por su dama argumenta de esta misma manera al defenderse de los abusos del poder ilimitado que quiere ejercer sobre ellos el conde de San Pol, representante del rey ${ }^{7}$. Maravall (1997: 381-382) lo explica con mucha claridad cuando advierte en estos escritores que la fe que dirige la razón es también la fe

5. Se trata también de la llamada simulación, que tanto debate produjo después. Ver Maquiavelo, El principe, p. 72: «Un príncipe no ha de tener necesariamente todas las cualidades citadas, pero es muy necesario que parezca que las tienen». La idea aparece, entre otros, en Fernández de la Mora (1949: 435).

6. Cf. igualmente Duarte (2012).

7. Bances 1997: vv. 3144 y ss. : «Ernesto: Los vasallos no le atajan / al rey el poder, sino / la razón que tienen para / que el poder se ajuste a ella, / y así advertid que se llama / imperfección del poder / poder hacer cosas malas, / y ha de obedecerse a sí / primero aquel que a otros manda, / para que así con su ejemplo / consecuencia a todos haga» (Cursivas mías). 
que dirige la razón de Estado y se dará entonces la verdadera razón de Estado que ofrece Ribadeneyra a disposición del príncipe cristiano:

La legítima razón de Estado obliga a contar con la fe y respetar sus principios, en primer lugar porque Dios lo manda así, y es forzoso fundamento de racionalidad en el hombre obedecer a Dios Todopoderoso, en cuya mano está el destino de todo lo humano.

En el teatro de Bances, he encontrado en dos ocasiones el polémico término de la «razón de Estado» ${ }^{8}$ citado por dos mujeres que han de casarse obligadas por su familia a un matrimonio que no desean?. Estos ejemplos llaman la atención porque muestran cómo este concepto de «razón de Estado» atropella la libertad humana.

Otra idea que aparece a menudo es la de la esclavitud del oficio del gobierno. El gobernante resulta ser el más infeliz de todos los hombres, porque debe servir a todos los demás en una tarea pesada e ingrata. Así lo expresa el rey de Polonia en Sangre, valor y fortuna ${ }^{10}$, la reina Cristina de Suecia en Quien es quien premia al amor ${ }^{11}$, el rey Hispán en La piedra filosofal se queja de tener que cumplir con sus deberes de gobierno cuando los demás se divierten en las fiestas ${ }^{12}$ y en El esclavo en grillos de oro, Trajano advierte a Camilo de las penalidades y sufrimientos que debe padecer el gobernante ${ }^{13}$.

La siguiente idea que me interesa destacar es la del vencimiento de las pasiones por parte del gobernante, que puede regir con rectitud la vida de sus súbditos, si se domina a sí mismo. Encontramos numerosos ejemplos: el rey de Polonia en Sangre, valor y fortuna, deseando vengar la muerte de su hijo, al final aplica la justicia y la clemencia ${ }^{14}$; en La piedra filosofal (vv. 1785 y ss.), el mago Rocas le insiste a Hispalo que lo más importante es vencer por medio de su libre albedrío sus pasiones y la influencia de los astros y encontramos muchísimos más casos.

8. El término «razón de Estado» nunca fue utilizado por Maquiavelo y, sin embargo, derivado de sus teorías, resultó ser una de las ideas más fecundas y contrastadas por parte de los escritores católicos a partir de las doctrinas del florentino.

9. Ver Bances, La piedra filosofal, vv. 1391-1400 y El esclavo en grillos de oro, vv. 2961-2970.

10. Bances, Sangre, valor y fortuna, v. 2000 : «Bien dicen que el más rey es más esclavo».

11. Bances, Quién es quien premia al amor, vv. 353-354 : «iAy, si supieras por eso / cuánto el ser reina me cansa».

12. Op. cit., vv. 2687-2691: «iOh tarea de despacho, / no hay fiestas, no hay regocijos / en que permitas descanso, / porque se descuidan todos / a cuenta de mi cuidado».

13. Op. cit., vv. 1257-1264: «Por mí y por todo el Senado, / gustoso y agradecido / de que siendo el de monarca / un tan penoso ejercicio, / una fatiga tan grande / y un trabajo tan continuo, / que no hay en algún mortal / fuerzas para resistirlo». Camilo, más tarde, se da cuenta de las penalidades del oficio y se compara con el esclavo, ibid., vv. 2467-2471: "Camilo: Pues si tiene libertad / el más humilde plebeyo, / y aun para el libre albedrío / por monarca no le tengo, / ¿qué más esclavo que yo?».

14. Op. cit., vv. 2470-2472 : «Así me venzo a mí mismo, / y viene a tener el reino / lo que pedía». 
Este es un tópico, que ya nace en Platón o Séneca (Arellano 2011b: 148, n. 9), y se repite con cierta abundancia en la literatura política como analiza Maravall (249-250) y muestra, por ejemplo, Saavedra Fajardo:

Estos desórdenes de ambición los cría el largo uso de la dominación, que todo lo quiere para sí, en que es menester que los príncipes se venzan a sí mismos, se rindan a la razón, aunque es bien dificultosa la empresa; porque muchos pudieron vencer a otros, pocos a sí mismos. Aquella es victoria de la fuerza, esta de la razón. No está la valentía en vencer las batallas, sino en vencer las pasiones (1999: 513, «Empresa 41»).

Interesante puede ser el pensamiento de Bances que explica que el estudioso no puede ser un buen gobernante. Es el rey, hereditario o elegido, el que tiene la capacidad de sortear las dificultades del gobierno, lo que no alcanzará nunca el intelectual. En Por su rey y por su dama, el conde de San Pol defiende que el estudio no alcanza algunas verdades que encuentra en su labor el gobernante, contestando así a una crítica que le ha realizado su criado ${ }^{15}$. En La piedra filosofal, Hispán quiere contar en su gobierno con los consejos del sabio Rocas y este explica que el gobierno depende más de la experiencia que de la sabiduría ${ }^{16} . E l$ esclavo en grillos de oro es una de las piezas importantes en la que se desarrolla con cierta extensión esta idea. El ambicioso Camilo es un estudioso que está acostumbrado a la quietud y comodidad de su despacho, por lo que no puede adaptarse al ritmo y a la toma de rápidas decisiones que le exige la labor de gobierno:

$\begin{array}{ll}\text { Trajano } & \text { He conocido en Camilo } \\ \text { una complexión muy débil } \\ \text { para cualquier fatiga; } \\ \text { y está ya, aunque más se esfuerce, } \\ \text { cansado de tanto afán } \\ \text { y es preciso que desee } \\ \text { los ocios de hombre estudioso, } \\ \text { que las ciencias no se adquieren } \\ \text { sin un ánimo tranquilo, } \\ \text { ocioso e independiente (3319 y ss.). }\end{array}$

Sin embargo, la historia y la geografía desempeñan un papel muy importante en la labor del gobernante. Es interesante ver cómo valora Bances el papel del historiador. En La piedra filosofal, el criado Lico se da cuenta de la responsabilidad de la historia y el historiador al tener que transmitir con veracidad a las generaciones futuras los acontecimientos presentes:

15. Op. cit., vv. 1503-1505: "Ciertas materias de estado / que nacen con el dosel / no las conoce el estudio".

16. Op. cit., vv. 3058 y ss.: «¡Ay, señor!, / que el mandar lo dilatado / de un reino consiste más / en lo experto que en lo sabio, / y de mi quietud mal puedes / aprender a gobernarlo, / pues esa ciencia se estudia / viendo, que no contemplando». 
Lico

Eso

fuera muy bueno vedarlo

y aun castigarlo también,

a pocos hombres dejando

meterse a escribir historias,

que han de ser muy señalados

los que son en sus escritos

jueces de los soberanos

y árbitros en su conciencia

del futuro honor de tantos.

Mas ¿quién me mete a mí en esto? (vv. 2940 y ss.).

En El esclavo en grillos de oro, Trajano defiende que la experiencia puede ser escuela muy dura para aprender, ya que hay errores que pueden costar la vida al gobernante (vv. 663 y ss.). Maravall (1997: 65-69) explicaba que en el XVII la historia tiene una finalidad pública, ya que no se escriben las cosas para que no se olviden, sino para que enseñen a vivir, porque la imitación de las glorias y los errores pasados instruyen en el gobierno. En los tratados políticos de la época, se advierte que no hay vida más dificultosa que la del gobernante y la historia le puede resultar muy útil, debido a que conecta el presente, el pasado y el futuro, al prevenir el futuro conociendo el pasado. Pero la historia ha de ser coronada por la política: en el arte de la política no es posible la exactitud de la ciencia, es decir, calcular con precisión la reacción de los súbditos. El comportamiento de los ciudadanos es complejo y depende de una mezcla de pasiones, libertad y servidumbre. El mañana nunca es un calco del pasado.

\section{Malos gobernantes o malas acciones De gobierno}

Voy a comentar dos comedias de Bances Candamo, Por su rey y por su dama y El esclavo en grillos de oro, para ejemplificar los modelos de malos gobernantes que el autor construye en su teatro y que justifican esa pedagogía del gobierno que Bances defiende en su teorización del teatro ${ }^{17}$.

\section{Por su rey y por su dama}

Se trata de la primera comedia que conservamos de Bances Candamo escrita en 1685. Se inspira en el hecho histórico de la toma de Amiens por el héroe Hernán Tello Portocarrero cuando, con la astucia de bloquear el rastrillo de una de las puertas de la ciudad con un carro reforzado, consigue penetrar con sus tropas en esa ciudad francesa la mañana del 11 de marzo de 1597. Sin embargo, duró muy poco en manos de los españoles, ya que el 4 de septiembre de ese mismo año, los franceses la asaltan muriendo el propio Portocarrero en el combate.

17. Un repaso a los malos gobernantes de Calderón se encuentra en el interesante artículo de Arellano (2006). 
La comedia trata de esta conquista de la ciudad ya que el héroe español, Portocarrero, se ha enamorado de una dama francesa llamada Serafina, hija del gobernador. Como Portocarrero quiere servir a su dama, sirviendo además a su rey, decide conquistar la ciudad y casarse con la dama. El mal gobernante de esta comedia resulta ser el conde de San Pol, enviado por el propio rey francés para romper con alguna argucia las treguas con España y desplazar los ejércitos franceses contra los espańoles.

El primer problema que plantea el conde de San Pol es el deseo de ejercer un poder absoluto atropellando los derechos de los ciudadanos de Amiens, quienes defienden sus fueros y privilegios, por lo que no consienten que la ciudad sea defendida por los soldados, sino que ellos mismos se encargan de defenderla. Después de la celebración de un baile de máscaras, Portocarrero, que ha entrado disfrazado en la ciudad para ver a su amada francesa, es apresado, pero consigue escapar porque las autoridades francesas se enzarzan en una discusión de competencias para decidir quién debe custodiar al español.

Saavedra Fajardo, en sus Empresas politicas («Empresa 41», 512-513), explica los riesgos de una actitud como la del conde de San Pol, atribuyéndolo a la ambición, y destaca que ese deseo de poder absoluto puede acabar en tiranía:

Persuade la ambición desordenada el oprimir la libertad del pueblo, abajar la nobleza, deshacer los poderosos y reducillo todo a la autoridad real, juzgando que entonces estará más segura cuando fuere absoluta, y estuviere el pueblo más reducido a la servidumbre. [...]. La modestia es la que conserva los imperios, teniendo el príncipe tan corregida su ambición que mantenga dentro de los límites de la razón la potestad de su dignidad, el grado de la nobleza y la libertad del pueblo. [...]. El poder absoluto es tiranía. Quien le procura, procura su ruina.

El propio Mariana habla de cómo limitar el poder del rey, pues aunque mantenga importantes facultades como declarar la guerra, nombrar jueces, administrar justicia o establecer los magistrados, no es bueno que la comunidad le transmita un poder ilimitado:

El poder regio merece verdaderamente este nombre cuando se contiene dentro de los límites de la moderación y la templanza, pero se corrompe y pierde vigor cuando abusa del poder, como algunos imprudentes quieren hacer de día en día. [...] Nuestros antepasados, previeron como hombres prudentes este peligro y sancionaron muchas y muy sabias medidas para que los reyes se contuvieran en los límites de la moderación y la templanza y no pudieran ejercer una potestad excesiva de la que derivara un daño público (libro I, cap. VIII: 100-101).

Frente a los problemas evidentes de competencias de las autoridades francesas, las españolas funcionan con total perfección. El archiduque Alberto, encargado del gobierno de los Países Bajos, otorga todo el material bélico y los soldados necesarios para la toma de Amiens, aunque no sabe exactamente a qué objetivo se van a destinar. Se preocupa por el estado de sus tropas y sus 
súbditos, además de enviarle a Portocarrero el cargo de general de batalla para que no tenga ningún problema al imponer su autoridad (vv. 2449 y ss. ${ }^{18}$.

El segundo problema grave del conde de san Pol es la lujuria. A pesar de estar casado con Madama de san Pol, a la que lleva con él a la ciudad de Amiens, se encapricha de Serafina, amada por un súbdito suyo, Carlos Dumelino, y que al final se casará con el héroe español Hernán Tello Portocarrero. Carlos Dumelino lleva tiempo cortejando a Serafina con la que se quiere casar, sin embargo, el conde de san Pol lo humilla públicamente por eso y le quiere golpear con un bastón en medio de un baile por interponerse delante de la dama. Esta actitud del poderoso es recriminada con dureza por su criado, Renolt:

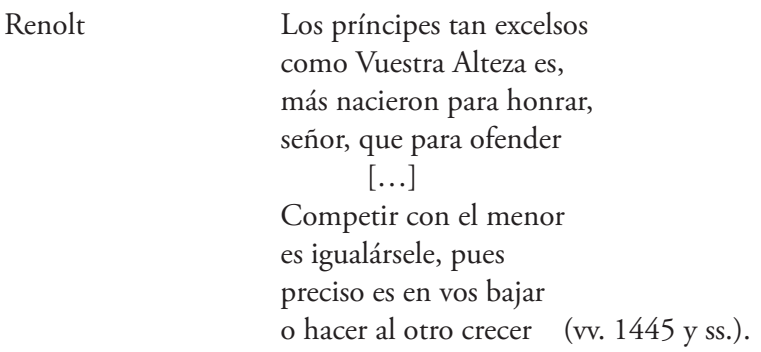

La lujuria es otro de los vicios de los gobernantes criticado por los tratadistas políticos. Ribadeneyra explica con detalle el problema:

Por otra parte, vemos que los príncipes muchas veces pierden sus vidas y Estados por entregarse al deleite sin freno, y seguir, como bestias, su apetito sensual; porque cuando el príncipe hace fuerza a mujeres honradas, como la injuria toca a la honra de sus maridos, padres, hermanos y deudos, y se tiene por injuria universal de todos (porque ninguno se tiene por seguro), cobran todos generalmente gran aborrecimiento al príncipe y procuran vengarse (libro II, cap. 22: 146) ${ }^{19}$.

Esta situación que describe Ribadeneyra es lo que ocurre con el súbdito francés Carlos Dumelino. Acusado y sentenciado a muerte por un pretexto político fingido (vv. 2689 y ss.), consigue escapar y pasarse al bando de los españoles para vengarse de la ofensa recibida.

La comedia acaba con la huida del tirano conde de San Pol de Amiens. Sin embargo, el personaje no se da cuenta de los errores cometidos, sino que sigue culpando a los privilegios de los ciudadanos la derrota inflingida por los españoles.

18. Ver Sanz Ayán (2006: 133): «El protagonista defendía explícitamente la puesta en práctica de una filosofía política en la que el pragmatismo, aderezado con ciertas dosis de prudencia y ejemplo de la historia, fueran las claves de actuación en los asuntos de Estado tal y como propugnaban desde el género de los tratados regio-políticos algunos de los que pretendían acceder al poder por esos años o ya lo habían hecho».

19. Lo mismo opina Mariana, La dignidad del rey, cap. XII, pp. 231-232 : «Huya de la liviandad y no se deje corromper por los placeres de la lujuria. No atente al pudor ajeno, dańo vergonzoso y grave que ofende a muchos y concita el odio del pueblo». 
Conde
Si eso aconsejan las canas, no el valor, y vive Dios pues el caso os desengaña de que vuestros fueros son de vuestra pérdida causa, pues si soldados hubieran, nunca la empresa lograran (vv. 3436-3442).

En este episodio podemos observar el trabajo de Bances con el decoro dramático, ya que el conde de san Pol sale de la ciudad luchando con sus soldados y demostrando su valor con su espada: «[de la ciudad] el conde falta, / que, espada en mano, rompiendo / cuantos batallones halla / salió de la plaza» (vv. 3462-3465). Si tenemos en cuenta las fuentes históricas que narran el episodio, veremos que reflejan otro personaje, cobarde y timorato. Carlos Coloma, en su obra Las guerras de los Estados bajos, describe así esta peripecia:

No tuvo mejor fortuna que esta el conde de San Pol; porque, incrédulo al principio en alboroto, todo lo que dilató en salvarse le vino a faltar de tiempo para hacerlo sin conocido peligro, que al fin hubo de salirse a pie por una de aquellas puertas de la parte de Francia, con tanto recelo de que le siguiesen, que dicen ofreció quinientos ducados a la centinela francesa, que todavía estaba sobre la puerta, porque salido él y sus caballos, que le venían siguiendo, dejase caer el rastrillo, como lo hizo, con provecho del conde y daño de otros muchos que a esta causa quedaron en prisión (cap. X: 583).

\section{El esclavo en grillos de oro}

Esta comedia, representada en $1692^{20}$, es uno de los análisis políticos más sutiles de Bances Candamo. En ella se nos muestran con mucha precisión los errores de los malos gobernantes y los malos consejeros que le acompañan en su labor de gobierno.

El argumento es sencillo: ambientada en Roma, tras la llegada triunfal de Trajano y su sobrino Adriano, el consejero Cleantes descubre una conspiración por parte de Camilo para asesinar a Trajano y ocupar el poder. Sorprendentemente, el emperador Trajano, modelo de buen gobernante, decide castigar a Camilo entregándole el poder y nombrándolo sucesor suyo, si llega a superar quince días de prueba. Voy a analizar la figura del mal gobernante comparándolas con las de Trajano y Adriano, utilizando para ello los pasajes que nos proporcionan los tratadistas políticos católicos.

Camilo es un gobernante que sigue las doctrinas de Maquiavelo. Defiende el poder absoluto, independizado de cualquier limitación que llegue a maniatar la justicia, haciendo incluso lo injusto:

20. Según Moir, en Teatro de los teatros, op. cit, p. xxx, esta obra se representó a fines de octubre y no el 20 de noviembre de 1692 como defendía Cuervo Arango. 
Camilo Cuando delinque el poder, a la justicia le ata las manos el poder mismo; y la culpa que en él recarga, queda tal vez permitida y tal vez autorizada (vv. 237-242).

Además, tiene una visión cínica de la historia, porque para Camilo, esta la escriben siempre los vencedores, idea que contrasta con lo que expresaba Lico en La piedra filosofal:

Camilo

\author{
Ya sé, Lidoro, \\ lo que aventura mi fama \\ en acción tan peligrosa: \\ si en perderla o en ganarla \\ consiste en ser mala o buena, \\ y ha de quedar reputada \\ si se pierde, de traición \\ y si se logra, de hazaña (vv. 187-194).
}

Además, es un hombre sin experiencia. Mientras Camilo se ha dedicado a divertirse («él solo en divertimentos, / que a costa suya le infaman / lo rico, con lo soberbio" vv. 488-490), y a tratar de sus estudios, Trajano y Adriano han estado al frente de sus ejércitos:

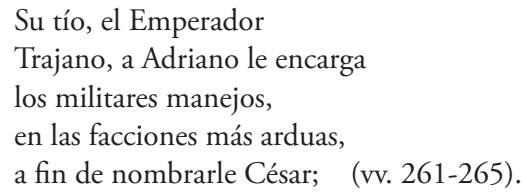

Este es un ejemplo curioso porque Quevedo ${ }^{21}$ o Mariana (1981: libro 3, cap. VI: 320 y ss.) recomendaban al príncipe cristiano ponerse al frente de los ejércitos para ir a la guerra, como precisamente han hecho Trajano y Adriano.

Otro de los defectos de Camilo es su excesiva ambición, pecado que le lleva a no poder disfrutar del poder cuando ya lo ha conseguido:

$$
\begin{array}{ll}
\text { Camilo } & \text { Solo todos me han dejado } \\
& \text { y el imperio conseguido } \\
& \text { no me parece, adquirido } \\
& \text { tanto como imaginado (vv. 1607-1610). }
\end{array}
$$

Esto le ocurre porque no entiende, como explica Trajano, que la felicidad está dentro de cada uno y que el hombre en sí vale muchísimo más que el ejercicio del poder.

Una vez en el poder, es inaccesible, ya que su criado Gelanor no puede llegar hasta él: 
Gelanor

Hame costado el entrar

mucho golpe y más temor;

porque tu guarda, Señor,

de mí te quiere guardar (vv. 1657-1660).

Maravall (1997: 330) estudia cómo los tratadistas indican que el príncipe ha de dar audiencia a todos con las mismas facilidades, siendo este un elemento básico de la administración de justicia.

El último gran defecto de Camilo es su incapacidad para dominar sus emociones. Cuando Cleantes le informa que debe dar su consentimiento para que su amada Sirene se case con su rival, Adriano monta en cólera y derriba el bufete en el que está escribiendo. El problema está en que ve en Adriano un rival, en lugar de ver un súbdito al que respetar. Por eso Cleantes le advierte :

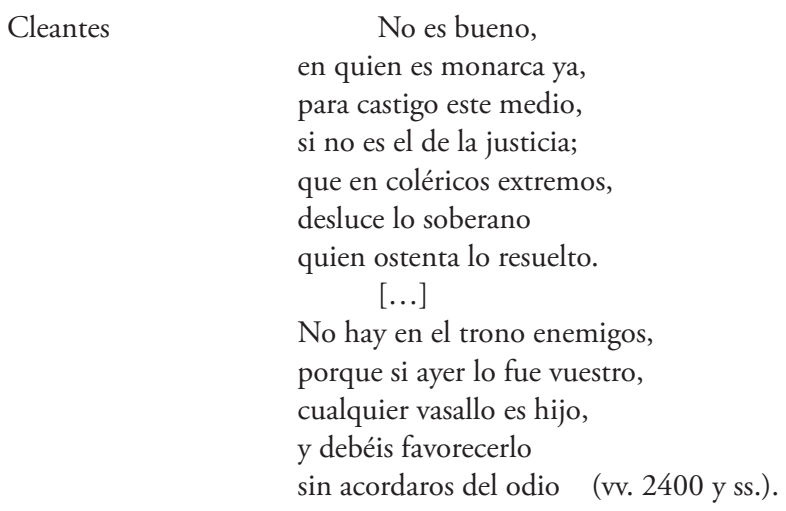

Maravall lo explica con gran lucidez. Camilo es un servidor de hombres libres, porque reinar es ejercer el señorío sobre hombres libres, ya que en los tratados políticos se diferencia entre el dominio y el imperio : el dominio proporciona al que lo ejerce el placer por lo dominado para su bien, mientas que el imperio busca el bien y la utilidad de los gobernados. Pero el imperio, además, implica la colaboración del gobernado de forma activa. En este caso, además, la ira que muestra Camilo descompone su poder como explica Mariana (1981: libro II, cap. XII, p. 234):

el dejarse vencer por la ira es la mayor prueba de un carácter débil y abatido, y que los más propensos a ella son los menos fuertes por edad y por sexo, tales como el anciano, la mujer o el niño. Por el contrario, es de ánimos grandes no irritarse ni darse por ofendido de una injuria.

Esta figura del mal gobernante queda complementada por la del mal consejero: Lidoro. Este coincide con su señor en su ambición sin límites basada en un poder absoluto (2860 y ss.), sin obstáculos ya que para él el poder lo puede todo : 
Lidoro

Señor, no a tantos discursos

el supremo poder rindas:

quien puede, todo lo puede,

y estas son sofisterías

de políticos (vv. 2903 y ss.).

Sin embargo, Camilo se da cuenta inmediatamente de que lo que le está aconsejando es precisamente la tiranía :

Camilo

Lidoro,

mal tu lealtad acreditas

en esos consejos; yo

soy monarca, y no querría

ser malo, por ningún caso :

pues aunque por tiranía

quise empezar mi corona,

no pensaba proseguirla

por ella, que la razón

cierta oculta simpatía

tiene al bien, $\mathrm{y}$ horror al mal

aunque dél un bien se siga ${ }^{22}$ (vv. 2912 y ss.).

Este pasaje me parece muy interesante ya que encontramos algunos elementos propios de la razón de estado : la razón, el bien, el mal, el bien político conseguido a través de cierta acción repugnante...

Es más; esa acción repugnante se fragua más adelante cuando Lidoro aconseja a Camilo que envenene a Adriano, a su enemigo. Es el asesinato desde el poder:

Lidoro

Tú eres monarca,

$y$ es en vano que te quejes,

ni que en tu poder inmenso

lo que puedes mandar ruegues.

¿Para cuándo es la violencia,

pues ya decretada tienes

la muerte de Adriano? (vv. 3175 y ss.).

Camilo se da cuenta de que Lidoro solo le apoya por su propio interés (vv. 3265 y ss.) y descubre la soledad del poder; el gobernante no tiene amigos, como le explica Tajano : «hay muy pocos / que hablen la verdad a un monarca, / y es el dolor más penoso / que tuve en cuanto mandé, / pues si alguna verdad toco, / es porque la discurro, / pero no porque la oigo» (vv. 3562 y ss.).

Podemos concluir diciendo que lo que salva al personaje de Camilo es la idea de decoro propia de Bances que impide que cometa el asesinato de Adriano o

22. Este pasaje recuerda el consejo de Maquiavelo sobre el uso de la violencia y las crueldades. Ver Maquiavelo, El principe, op. cit., p. 37: «Bien usadas pueden llamarse aquellas crueldades que ( si del mal es lícito hablar bien ) se hacen de golpe por la necesidad de afianzarse en el poder, y sobre las que luego no se insiste, sino que por el contrario se convierten, en lo posible, en una gran utilidad para los súbditos». 
que acabe su gobierno en tiranía, a pesar de los malos consejos de Lidoro. Al final, Camilo, desolado, devolverá el poder a Trajano porque ha comprendido la inmensidad de la tarea que debía realizar.

\section{Conclusiones}

Acabo de exponer una selección de ideas políticas que desgrana Bances Candamo en su teatro a través del análisis de algunos malos gobernantes y apoyado en el uso de autoridades que, estoy convencido, Bances manejaba. Evidentemente, en este poeta no encontramos un detallado proyecto de gobierno, porque esa no era la función del escritor y además el género teatral no se adapta bien a esto.

Lo que sí podemos encontrar, tal y como manifiesta en su teoría dramática expresada en el Teatro de los teatros, es una intención didáctica, mostrando al rey algunas ideas fundamentales que articulan su teatro y modelos que podían ayudarle a tomar determinadas decisiones. Algunos críticos han defendido una cierta influencia de Maquiavelo en las actitudes de los personajes o mediante la utilización de determinados términos: fortuna o virtud. Lo cierto es que hay gran coincidencia entre lo que expresan los tratadistas católicos, aquellas autoridades que se enfrentaban a las doctrinas del florentino, y Bances, buscando todos una nueva forma de hacer una política más justa, más humana y más eficaz: la llamada verdadera razón de Estado.

Bances presenta ciertos modelos que recuerdan a Maquiavelo: el poder absoluto, independiente de cualquier limitación, la ruptura de la palabra dada, el poder para satisfacer las ambiciones del poderoso, el crimen por razón de Estado. Pero estas ideas que refleja en alguno de sus personajes son un modelo, recordemos, que acaba en estrepitoso fracaso. Desde su puesto privilegiado de "poeta oficial de la corte» desgrana virtudes y actitudes que tienen más que ver con la educación del príncipe cristiano.

\section{Bibliografía}

Arellano Ignacio, «Bances Candamo, poeta áulico. Teoría y práctica en el teatro cortesano del postrer Siglo de Oro", Iberoromania, 1988, 27-28, pp. 42-60.

— "Decid al rey cuanto yerra”. Algunos modelos de mal rey en Calderón», en El teatro clásico español a través de sus monarcas, ed. Luciano García Lorenzo, Madrid, Fundamentos, 2006, pp. 221-237

— «La imagen del poder en el teatro de Bances Candamo, poeta áulico de Carlos II», en Los rostros del poder en el Siglo de Oro. Ingenio y espectáculo, Sevilla, Renacimiento, 2011a, p. 219-240.

— «Poder, autoridad y desautorización en el teatro de Calderón», en Los rostros del poder en el Siglo de Oro. Ingenio y espectáculo, Sevilla, Renacimiento, 2011b, p. 143169. 
Arredondo, María Soledad, «Armas de papel. Quevedo y sus contemporáneos ante la guerra de Cataluña», La Perinola, 1998, 2, p. 138-141.

Bances Candamo, Francisco Antonio, El esclavo en grillos de oro y La piedra filosofal, ed. Carmen Díaz Castañón, Oviedo, Biblioteca Académica Asturiana, 1983, 347 p.

- La piedra filosofal, ed. Alfonso D’Agostino, Roma, Bulzoni, 1988, 395 p.

- La restauración de Buda, ed. J. Enrique Duarte, en Francisco Antonio Bances Candamo, Poesías cómicas, I, 1, Obras completas, ed. Blanca Oteiza, Madrid / Frankfurt, Iberoamericana / Vervuert, 2014, p. 457-673.

- Por su rey y por su dama, o las máscaras de Amiens, ed. Santiago García Castañón, Oviedo, Real Instituto de Estudios Asturianos, 1997, 214 p.

- Quién es quien premia al amor, ed. Blanca Oteiza, en Francisco Antonio Bances Candamo, Poesías cómicas, I, 1, Obras completas, ed. Blanca Oteiza, Madrid / Frankfurt, Iberoamericana / Vervuert, 2014, p. 241-436.

- Sangre, valor y fortuna, ed. Santiago García Castañón, Oviedo, Instituto de Estudios Asturianos, 1991, $196 \mathrm{p}$.

- Teatro de los teatros de los pasados y presentes siglos, ed. Duncan W. Moir, London, Tamesis Books, 1970, $191 \mathrm{p}$.

Botero Giovanni, La razón de Estado y otros escritos, ed. Luciana de Stefano y Manuel García-Pelayo, Caracas, Instituto de Estudios políticos, Facultad de DerechoUniversidad Central de Venezuela, 1962, 249 p.

Coloma de Saa Carlos, Las Guerras de los Estados Bajos. (Desde el año 1588 hasta el de 1599), Madrid, Ministerio de Defensa, 2010, 766 p.

Duarte J. Enrique, «Poesía e historia en La restauración de Buda de Francisco Bances Candamo", en Similitud y verosimilitud en el teatro del Siglo de Oro. Coloquio Internacional elaborado por el Laboratorio de Investigaciones: lenguas y literaturas románicas, E. A. 1925. Pau, 21 y 22 de noviembre de 2003, ed. Isabel Ibáñez, Pamplona, Eunsa, 2005, p. 283-307.

- «La exaltación de la casa de Austria y España en La restauración de Buda y El Austria en Jerusalén de Bances Candamo", en La voz de Clio: imágenes del poder en la comedia histórica del Siglo de Oro, ed. Oana Andreia Sâmbrian, Craiova, Editura Universitaria-Universitatea din Craiova, 2012, p. 116-130.

Fernández de la Mora Gonzalo, «Maquiavelo visto por los tratadistas políticos españoles de la contrarreforma», Arbor, 1949, 13, p. 417-449.

García Castañón, Santiago, "Corrientes del pensamiento maquiavélico en una comedia inédita de Bances Candamo», Cuadernos de Aldeeu, 7, 1991a, p. 19-29.

- «Introducción a Sangre, valor y fortuna», en Francisco Bances Candamo, Sangre, valor y fortuna, ed. Santiago García Castañón, Oviedo, Instituto de Estudios Asturianos, 1991b, p. 7-96.

Maquiavelo Nicolás, «Discursos sobre la Primera década de Tito Livio», en Obras, ed. Juan A. G. Larraya, Barcelona, Editorial Vergara, 1961, p. 241-829.

- El príncipe, ed. Helena Puigdomènech Forcada y Ana Martínez Arancón, Madrid, Tecnos, 2010, 111 p.

Maravall José Antonio, Teoría del estado en España en el siglo XVII, Madrid, Centro de Estudios Constitucionales, 1997, 423 p.

Mariana Juan de, La dignidad del rey y la educación del rey (De rege et regis institutione), 
ed. Luis Sánchez Agesta, Madrid, Centro de Estudios Constitucionales, 1981, 481 p.

Oteiza Pérez Blanca, "Las "autoridades” de Bances Candamo, poeta dramático», en El autor en el Siglo de Oro. Su estatus intelectual y social, ed. Manfred Tietz, et al., Vigo, Academia del Hispanismo, 2011, p. 305-316.

Ribadeneyra Pedro de, Tratado de la religión y virtudes que debe tener el príncipe cristiano para gobernar y conservar sus estados, contra lo que Nicolás Maquiavelo y los politicos deste tiempo enseñan, ed. Ignacio Puig, Buenos Aires, Sopena, 1942, 199 p.

Saavedra Fajardo Diego de, Empresas políticas, ed. Sagrario López Poza, Madrid, Cátedra, 1999, 1077 p.

Sanz Ayán Carmen, Pedagogía de reyes: el teatro palaciego en el reinado de Carlos II: discurso leido el día 26 de febrero de 2006 en la recepción pública de la Excma. Sra. Doña Carmen Sanz Ayán y contestación por el Excmo. Sr. Don José Alcalá-Zamora y Queipo de Llano, Madrid, Real Academia de la Historia, 2006, 214 p. 
